\title{
MEDISCHE ONTWIKKELINGSSAMENWERKING IN CENTRAAL-AFRIKA
}

\author{
Andre DE SCHAEPDRYVER \\ Instituut J.F. en C. Heymans voor Farmacodynamica en Therapie \\ Universitair Ziekenhuis, R.U.G. \\ De Pintelaan 185 \\ 9000 Gent
}

ONDERZOEKSVELD: farmacologie

\section{$\underline{\text { SUMMARY }}$}

\section{MEDICAL DEVELOPMENT-COOPERATION IN CENTRAL AFRICA}

The author describes the Project of Medical Cooperation between the Medical Faculties of the University of Ghent and the National University of Rwanda in Butare.

The objectives of this project, which started in 1966, were the following:

(1) to organize and dispense the theoretical education and practical training at the G.P.-level;

(2) to structure the postgraduate education of alumni selected for higher education posts;

(3) to take care of the postgraduate training of specialists;

(4) to organize the continuing education of health personnel;

(5) to promote and participate in medical research.

The results of the Project were, in 1984:

(1) at the level of health personnel: the education and training of 220 physicians, 19 university lecturers and 15 specialists; 
(2) at the level of the infrastructure: the building of the Medical Faculty facilities, the pediatric and medical policlinics and clinics, the community health service for adults; the adaptation of the gynecological-obstetrical policlinic and clinic and of the community health service for children; the founding of the Faculty library, secretariat and workshop,

(3) at the research level: the founding and development of the University Center for Research on Traditional Pharmacopoeia and Medicine, aiming at:

a) the valorization and integration of traditional medicine;

b) the study of Rwandese medicinal plants;

c) the local production of pharmaceutical preparations of plant origin and organic raw materials.

The attention is drawn to the importance of the postgraduate education in Belgium, for periods of 5 years, of 25 Rwandese medical alumni, which resulted in 15 Ph.D. -theses and a nearly complete rwandization of the Faculty of Medicine and University Hospital in Butare.

A pairing Agreement Butare-Ghent has taken the relief of the Pro ject, insuring its continuity through visiting lecturers, and the coaching of trainees and of research projects in various fields of the local pathology.

\section{INLEIDING}

Nadat Rwanda op 1 juli 1962 tot onafhankelijke republiek was uitgeroepen, werd op 9 mei 1963 een aanvang gemaakt met het inrichten van het hoger onderwijs dank zij een conventie tussen de Rwandese Regering en de Paters Dominicanen van de Provincie Saint-Dominique in Canada.

De Université Nationale du Rwanda (U.N.R.) vestigde zich te Butare, het voormalige Astrida, in het zuiden van het land en nam haar intrek in een ruim pensionaat op een heuvel in de onmiddellijke omgeving van de Groupe Scolaire van de Broeders van Liefde en van het Institut National de Recherches Scientifiques (I.N.R.S.), erfgenaam van het voormalige Institut de Recherches Scientifiques en Afrique Centrale (I.R.S.A.C.).

De U.N.R. telde aanvankelijk 3 faculteiten : de Faculteit voor Sociale Wetenschappen, de Faculteit der Geneeskunde en de toenmalige Hogere Normaalschool, die reeds in 1964 werd gesplitst in de Faculteit der Rechten en de Faculteit der Wetenschappen. De opening had plaats op 3 november 
1963. Er waren toen 16 professoren en 51 studenten.

Met de steun van de Canadese Regering werd een ruim bouwprogramma op gang gebracht dat een snelle ontwikkeling van de 4 Faculteiten, met uitzondering van de Faculteit der Geneeskunde, mogelijk maakte. Dat deze laatste nahinkte was aan verschillende oorzaken te wijten: het gebrek aan ervaring met de talrijke en complexe facetten die zich stellen bij de inrichting van een medische faculteit, het ontbreken van professoren met bevoegdheid op het gebied der tropische geneeskunde, de aanzienlijke financiële belasting ingevolge de noodzaak van een ver gediversifieerd onderwijs en niet in het minst de zeer zware en steeds in omvang toenemende ziekenzorguitgaven.

Dit bracht met zich dat Pater Levecque, Rector van de U.N.R., zijn collega Prof. J.J. Bouckaert, Rector van de R.U.G., vroeg de organisatie en de wetenschappelijke, technische en financiële gestie van de Faculteit der Geneeskunde van de U.N.R. op zich te nemen.

Rector Bouckaert, gesensibiliseerd door zijn vroegere betrokkenheid bij de medische ontwikkelingssamenwerking in het N.O. van Belgische Congo, in het raam van de werkzaamheden van de Stichting Ganda-Congo, waaraan een einde was gesteld in 1960 bij de onafhankelijkheid van Zaire, aarzelde niet positief op dit verzoek in te gaan.

Prof. K. Vuylsteek werd belast met de organisatie van het doctoraatsonderwijs te Butare ter intentie van twee promoties Rwandese "assistants médicaux" die reeds een 15-tal jaren praktijk achter de rug hadden en die net een kandidatuursbijscholing aan de Faculteit der Wetenschappen van de U.N.R. hadden verworven.

Prof. K. Vuylsteek verkende zeer grondig het terrein, legde de nodige contacten met de lokale autoriteiten, ontwierp een passend curriculum, motiveerde te Gent collega's om te Butare blok- cursussen te gaan doceren, alsook recent afgestudeerde specialisten die aldaar de eerste ploeg permanante coöperanten zouden vormen, en verzekerde vervolgens vanuit België de administratieve coördinatie van de onderneming.

\section{DE CONVENTIE VAN 1966}

Aldus kon reeds op 21 oktober 1966 een samenwerkingsakkoord ondertekend worden tussen de U.N.R. en de R.U.G., vervolgens op 13 december 
1966 een conventie tussen Rwanda en België en ten slotte op 19 september 1967 een contract tussen de Belgische Regering en de R.U.G. Volgens de termen van deze overeenkomsten zou de Faculteit der Geneeskunde van de R.U.G. het wetenschappelijk, technisch en financieel beheer van de Faculté de Médecine van de U.N.R. op zich nemen en werd aan deze laatste een dubbel statuut toegewezen : enerzijds zoals voor de U.N.R. bepaald door de Wet van 12 mei 1964, en anderzijds zoals bepaald door de Belgisch-Rwandese Conventie. Zo dit speciaal statuut meer armslag gaf bij het inrichten van het medisch curriculum en een soepeler functioneren van de Faculteit toeliet, was het voor de Faculteit niet al goud wat blonk, o.a. omdat zij van twee voogdijministers afhankelijk was, met name van het Ministère de l'Education als onderwijsinstelling en deel van de U.N.R., en van het Ministère de la Santé als verpleeginstelling. Hierin kwam in 1978 verandering tengoede, toen de volledige Faculté de Médicine, inclusief het Hôpital Universitaire, het Centre Universitaire de Santé Publique en de Laboratoires Universitaires, onder het Ministère de l'Education en nadien onder Ministère de l'Enseignement Supérieur et de la Recherche Scientifique kwamen te ressorteren.

De conventie van 1966 stelde de volgende duidelijke objectieven : (1) het verzekeren van de theoretische en praktische vorming van de toekomstige geneesheren; (2) het voorbereiden van Rwandese kandidaten op onderwijsen beheersfuncties in de Faculteit en bovengenoemde daaraan gehechte inrichtingen, (3) het organiseren van de goede functionering van het volledige medische complex van de U.N.R., d.w.z. de Faculté de Médicine, het Hópital Universitaire, de Laboratoires Universitaires en het Centre Universitaire de Santé Publique.

De eerste twee reeksen doctorandi waren sterk gemotiveerd. Het waren mannen van 30 a 40 jaar die als assistants médicaux reeds heel wat praktische ervaring hadden opgedaan en die in het voor hen ingerichte curriculum de kans van hun leven zagen.

In 1968 en 1969 promoveerden achtereenvolgens 9 en 6 gewezen assistants médicaux tot doctor in de geneeskunde en werden telkens 4 van deze twee groepen van gepromoveerden tot assistent bij de Faculteit aangesteld met de bedoeling ze voor te bereiden op onderwijsfuncties in de gebieden der chirurgie, histopathologie, O.R.L. en preventieve geneeskunde, voor de eerste groep, en in die der inwendige geneeskunde, pediatrie, gynaecologie- 
obstetrica en oftamologie, voor de tweede groep.

De Faculteit der Geneeskunde van de U.N.R. beschikte bij haar stichting over een ouderwets " Hôpital de territoire " en over een meer recente " Clinique pour personnes aisées " evenals over een " Pavillon Maternité ". De patiënten die zich voor ambulante verzorging aanboden waren onvoldoende onderzocht op het dispensarium-niveau terwijl de klinische diensten sterk leden onder de afwezighied van een adequate verpleegkundige infrastructuur en onder het chronisch tekort aan geneesmiddelen.

Dank zij de inbreng van het patrimonium van de stichting Ganda- Congo ging de R.U.G. over tot de bouw van een polikliniek en van een tandheelkundige afdeling, evenals van een heelkundig blok, voorzien van een dienst voor intensieve zorgen, en van een paviljoen voor kinderziekten.

Aanvankelijk werd het eerste deel van de medische opleiding, dat 1 jaar pre-medische en 2 jaar pre-klinische studies omvatte, te Butare verstrekt door Canadese leden van de U.N.R. en door medici van de Belgische Ontwikkelingssamenwerking.

Na de overname van de organisatie van de medische faculteit van de U.N.R. werd een bijzonder kandidatuuronderwijs ingericht, eerst te Gent, nadien te Luik, voor twee groepen van telkens 5 kandidaten. Toen dit systeem niet aan de gestelde verwachtingen bleek te voldoen werd besloten een volledige medische opleiding, gespreid over 6 jaren van ieder 2 semesters, te Butare zelf te verstrekken.

\section{DE 2e EN 3e CONVENTIE VAN 1969 EN 1974}

De tweede, in 1969 voor de duur van 5 jaar ondertekende conventie kende minder duidelijk omschreven objectieven dan de eerste: het aantal te vormen $R$ wandese studenten in de geneeskunde lag niet vast, evenmin als het aantal door België ter beschikking te stellen docenten. Niettemin werden de afspraken nageleefd en promoveerden de eerste volledig te Butare opgeleide geneesheren in 1973.

De derde conventie, in 1974 aangegaan voor een periode van 4 jaar, bracht 
een kentering ten goede, vnl. door het scherpstellen van de drie volgende objectieven: (a) het verzekeren van de theoretische en praktische opleiding van 15 tot 20 algemene practici per jaar, via een onderwijscyclus van 6 jaar met een programma dat stoelde op de conclusies van het Gisenyi-colloqium van 1973 en tevens, in een later stadium, op het Vijfjarenplan van de Rwandese regering voor de periode 1977-1981. Deze conclusies bepaalden dat de fundamentele politiek op het terrein van de volksgezondheid diende te steunen op een medische inzet gericht op de eerste lijnsbasisgezondheidszorgen, die 0.a. de preventie en elementaire zorgen aanbrengt aan groepen met hoog risico, d.w.z. kinderen, zwangere vrouwen, sommige werknemers... Dit onderwijsprogramma werd door de Faculteiten der Geneeskunde van de U.N.R. en van de R.U.G. voorgesteld en werd zowel door het Ministerie van Volksgezondheid als door het Ministerie van Nationale Opvoeding te Kigali goedgekeurd; b) bij de Rwandisering van faculteitsposten dienden de kandidaten hiervoor door de Faculteitsraad te worden voorgesteld en eveneens door beide bovengenoemde Ministeries te worden aanvaard; c) het ter- beschikking stellen vanuit België van een aantal specialisatiebeurzen, bestemd voor de bij- en nascholing van de eerste groep Rwandese specialisten die hun postgraduaatvorming in versneld tempo en in niet steeds optimale voorwaarden hadden moeten verwerven, en van een aantal assistentsschapsbeurzen, bestemd voor volledige postgraduaatopleiding in pre-klinische en klinische disciplines in België.

Er kan gesteld worden dat de objectieven van de derde conventie in belangrijke mate werden bereikt. De opleiding van het vooropgestelde aantal studenten werd verzekerd, al weze het dat nog onvoldoende aandacht besteed werd aan de preventieve geneeskunde. Van het echt Rwandiseren van verantwoordelijke posten kon vooralsnog niet veel werk worden gemaakt, wat gezien het gebrek aan een voldoende aantal grondig gevormde specialisten niet zo verwonderlijk was. Er werden specialisatiebeurzen in de chirurgie, anatomo-pathologie en oftalmologie toegekend en 12 assistentschapsbeurzen stelden een overeenstemmend aantal goed geselecteerde bursalen in de gelgenheid in de beste voorwaarden in België een postgraduaatopleiding te verwerven in de anatomie- embryologie, fysiologie, biochemie, anatomo-pathologie, anesthesiologie, pediatrie, chirurgie, gynaecologie-verloskunde, preventieve geneeskunde, microbiologie, oftalmologie en dermatologie. Dat het programma van de assistentbursalen - een vooruitziend initiatief van Prof. P.G.Janssens, toenmalig coördinator van het 


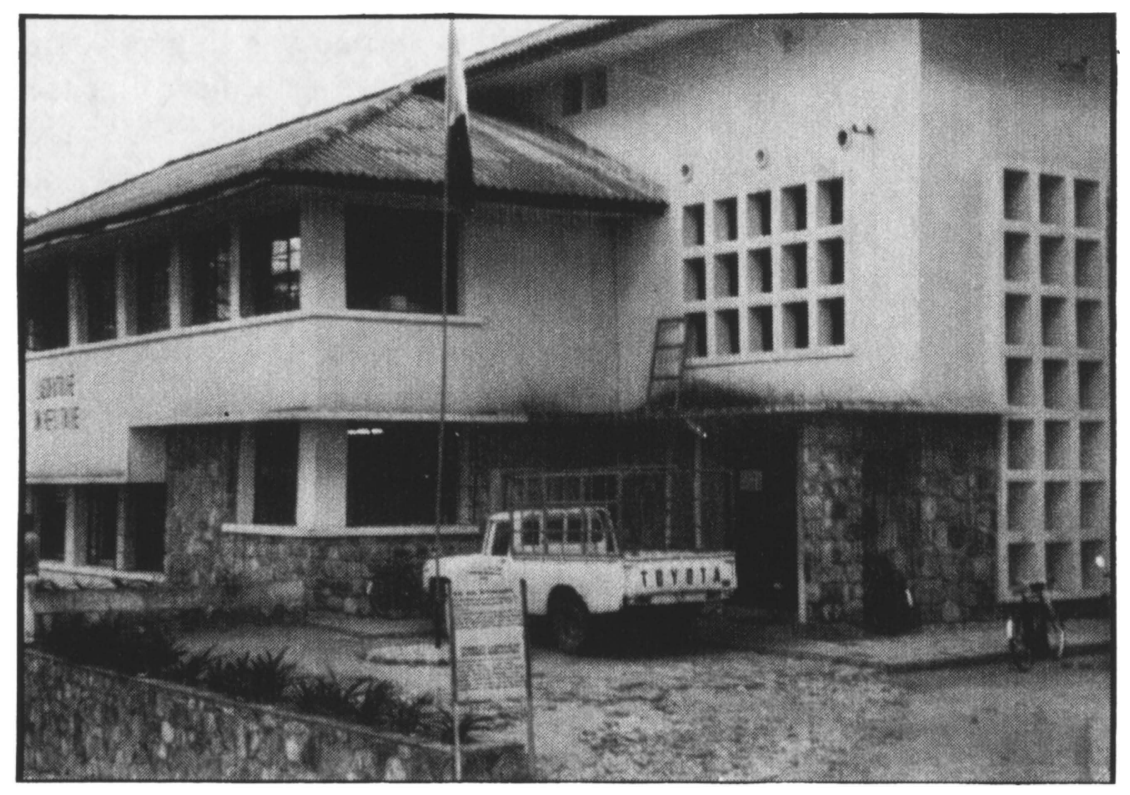

Laboratoria van de faculteit geneeskunde te Butare 
van het project - voor de ontwikkeling van de Rwandese Geneeskunde in het algemeen en die van de Faculté de Médecine van de U.N.R. in het bijzonder, van het allergrootste belang was, bleek ten volle vanaf 1981 wanneer deze bursalen na het in België verwerven van postgraduaatopleiding en -training, de door hen opgedane kennis en ervaring te Butare ten dienste van hun Universiteit en van hun land konden stellen.

In de loop van het academiejaar 1978-1979 kreeg de Faculté de Mé decine de l'U.N.R. drie evaluatiezendingen te last. Als lichtpunt in dit overgangsjaar dient vermeld te worden dat aan het Centre Universitaire de Santé Publique een 6-tal perifere antennes in de Prefectuur van Butare werden gehecht, waar de laatstejaars-stagiairs voortaan én maand stage zouden doorbrengen, waardoor het belang van de preventieve geneeskunde in het medische curriculum daadwerkelijk werd benadrukt.

Mede dank zij het voorbereidend werk van bovengenoemde evaluatiezendingen kon een Gemengde Belgisch-Rwandese Technische Commissie in oktober-november 1979 overgaan tot het opstellen van een duidelijk georiënteerde akkoordtekst van verdere ontwikkelingssamenwerking, die tevens zo naar inhoud als naar vorm de objectieven van de vierde conventie, slaand op de periode 1979-1983, in detail weergaf.

Wat het medisch onderwijs betreft, diende een kandidaat, die zich bij de Faculté de Médecine van de U.N.R. wenste te laten inschrijven, voortaan drager te zijn van een diploma van middelbaar onderwijs, gehomologeerd door het Ministerie van Nationale Opvoeding, of van een diploma dat door de toelatingscommissie van de U.N.R. als gelijkwaardig werd aangezien. Het medische curriculum omvatte vanaf 1981 (a) een pre-medisch oriëntatiejaar, verzorgd door de Faculteit der Wetenschappen van de U.N.R., (b) een eerste cyclus van fundamentele pre-klinische vorming, twee jaar omvattend en bekrachtigd door de toekenning van het universitaire diploma van "baccalaureat en biologie humaine" (c) een tweede cyclus van klinische vorming, drie jaar omvattend, waarvan een stagejaar, bekrachtigd door de toekenning van het einddiploma van doctor in de Geneeskunde. Het was de bedoeling de stage niet tot het Hopital Universitaire van Butare te beperken, doch deze uit te breiden tot prefectuur- en andere geaffilieerde hospitalen in Rwanda. Het nieuwe curriculum moest het ook mogelijke maken de duur van de stage "preventieve geneeskunde", waarbij meerdere dispensaria, nutritionele en andere medisch-sociale centra van het land betrokken werden, van 1 en 3 maanden te brengen. 
Dat het in de vierde conventie eindelijk emst was met de preventieve geneeskunde moge blijken uit het feit dat deze sector voor het eerst een eigen budget toebedeeld kreeg en dat twee van de acht voorziene permanente coöperanten-posten aan Santé Publique-experts werden toegewezen.

\section{HET RESEARCHPROJECT VAN HET CENTRE UNIVERSITAIRE DE RECHERCHE SUR LA PHARMACOPÉE ET LA MÉDICINE TRADITIONELLE (CURPHAMÉTRA)}

Het past hier even in te gaan op het reseachproject van het Centre Universitaire de Recherche sur la Pharmacopée et la Médecine Traditionnelle (Curphamétra) op dit ogenblik het enige operationele in de Faculté de Médicine van de U.N.R. Dit project, aanvankelijk uitsluitend, zij het op bescheiden wijze, gefinancierd door het project "Gent-Butare", heeft zijn ontstaan en ontwikkeling in overwegende mate te danken aan het initiatief en de aanstekelijke werklust van een Belgisch industrieel ingenieur, L. Van Puyvelde, die in 1970 als permanente coöperant het project vervoegde. Het feit dat de inlandse farmacopee in Rwanda een vrij belangrijke graad van ontwikkeling heeft bereikt en nog over het gehele land frequent wordt aangewend, in hoofdzaak door de guérisseurs en beoefenaars van de zgn. médicine traditionnelle, gepaard met de permanente nood aan dure westerse geneesmiddelen, brachten met zich dat de belangstelling gewekt werd door een gepland onderzoek naar de natuur en farmacologische eigenschappen van de planten die in de inlandse farmacopee voorkomen. Was de botanische systematiek van deze planten degelijk uitgewerkt, dan was het met de kennis van hun chemische identiteit en van hun farmacodynamie pover gesteld, uitgezonderd dat het wel algemeen geweten was dat sommige der alkaloïden waar het in deze plantenextracten om te doen is, zeer effectieve abortiva en anthelminthica zijn. In het raam van bovengenoemd project werd vooreerst, met de medewerking van prefets en guérisseurs, een nauwkeurig onderzoek ingesteld naar de bereidingswijzen, indicaties, gebruikswijzen, werkingen en bijwerkingen der in omloop zijnde inlandse geneesmiddelen van plantaardige oorsprong. Nadat deze inventaris was afgewerkt, werd overgegaan tot de extractie en zuivering en vervolgens tot de farmacologische screening der afzonderlijke componenten. Dit onderzoek is nu volop aan de gang, evenals het ophelderen van de structuurformules der actieve bestanddelen. 
Reeds nu worden conditioneringen van actieve bestanddelen uitgevoerd, uitgaand van Datura, Capsicum en Cinchona, evenals op basis van emodine en berberine. De produktie van grondstoffen, o.a. looistoffen, ethanol, zetmeel, diogenine (basisstof bij de hemisynthese van steroïden) is eveneens een economisch belangrijk luik van het project.

\section{BALANS EN DE VERWEZENLIJKINGEN VAN 18 JAAR ONTWIKKELINGSSAMENWERKING}

Dat de balans van 18 jaar ontwikkelingssamenwerking tussen de Faculteiten van Geneeskunde van de R.U.G. en van de U.N.R. als positief mag aangezien worden is in zeer ruime mate te danken aan de inzet en volharding van de 67 permanente en 47 tijdelijke Belgische coöperanten die bij het project betrokken waren.

De verwezenlijkingen situeren zich op verschillende niveaus.

Op onderwijsgebied werden 220 geneesheren gevormd, waarvan 25 verder tot docent en geneesheer-specialist in de verschillende pre-klinische en klinische disciplines werden opgeleid, wat tevens resulteerde in 18 aggregaats- en doctoraatsproefschriften en in de zo goed als volledig doorgetrokken Rwandisering van de Medische Faculteit te Butare.

Wat de infrastructuur betreft dienen vermeld te worden : de constructie van faculteitsgebouwen, de pediatrische en interne poliklinieken en klinieken, het dispensarium voor volwassenen, de verbouwing der polikliniek en kliniek voor gynaecologie en verloskunde en van het dispensarium voor kinderen, de inrichting van de bibliotheek en het secretariaat van de Faculteit en van een technische werkplaats.

Op het gebied van het wetenschappelijk onderzoek werd reeds geween op de oprichting en de activiteiten van het Centre Universitaire de Recherche sur la Pharmacopée et la Médecine Traditionnelle waarvan de objectieven zijn : de studie van Rwandese medicinale planten en de valorisatie van de traditionele geneeskunde, en de lokale produktie van plantaardige geneesmiddelen en van organische grondstoffen.

Sinds het beëindigen van het project, in 1984, wordt de ontwikkelingssamenwerking tussen de Faculteiten de Geneeskunde van de R.U.G. en van 


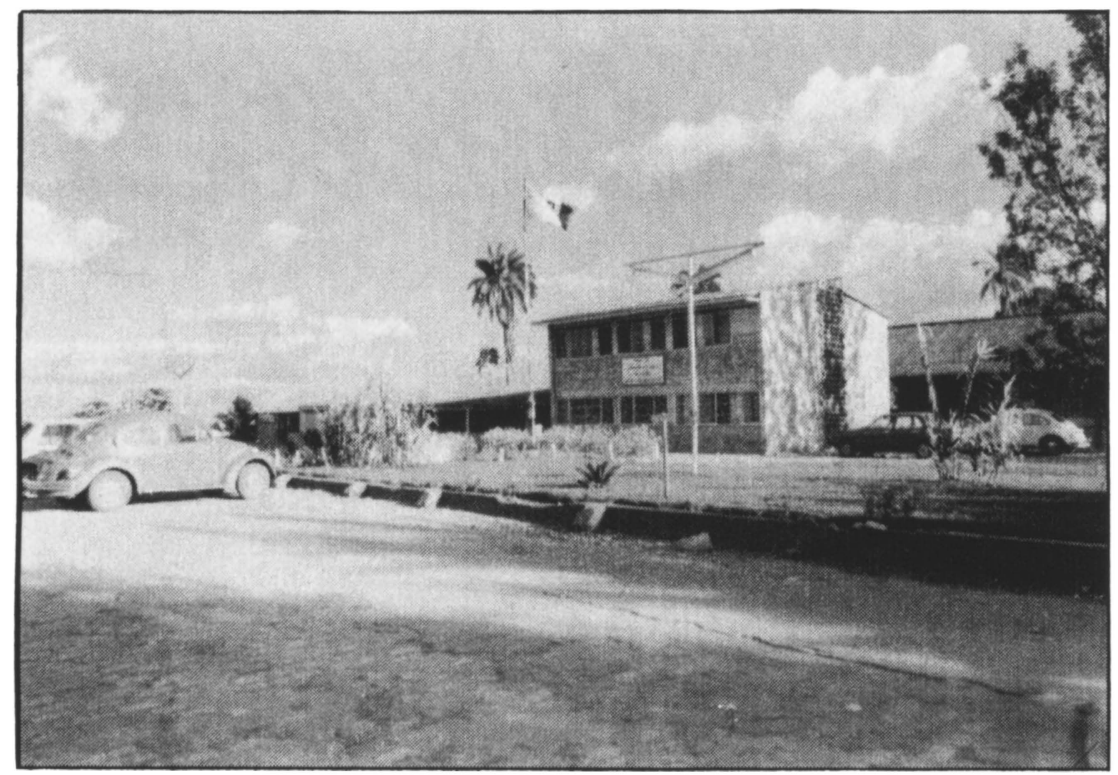

Het Universitair Hospitaal te Butare 
de U.N.R. verder gezet o.v.v. een jumelage- akkoord met de volgende opdrachten :

1) het verzekeren van een beperkt aantal onderwijsposten in sectoren waarvoor nog geen Rwandese homologen voorhanden zijn;

2) de opvang en begeleiding van jonge $R$ wandese assistent-bursalen die in België een specialistische opleiding komen verwerven ;

3) de bijscholing van Rwandese specialisten die reeds een aantal jaren praktijk te Butare hebben uitgeoefend ;

4) het ontwerpen en uitvoeren van onderzoeksprojecten in de labo ratoria en klinische diensten van de Faculteit der Geneeskunde te Butare.

Het relaas van een zo omvangrijk en langlopend project van ontwikkelingssamenwerking op de gebieden van het medisch onderwijs en van de ziekenzorg dient logischerwijze gevolgd te worden door een kritische bespreking ervan, gesitueerd in de ruimere context van de Noord-Zuid samenwerking en van de gezondheidsproblematiek eigen aan een klein, geografisch geïsoleerd, economisch zwak doch demografisch snel groeiend Centraal-Afrikaans land zoals Rwanda.

Wanneer wij nagaan waar de 220 Alumni van de Medische Faculteit te Butare hun beroep uitoefenen, stellen wij, vast dat $92 \%$ ervan in hospitalen werkzaam is. Deze hospitalen leggen overigens ook beslag op $65 \%$ van de verpleegsters en op $59 \%$ van de zgn. assistants médicaux. Dit betekent dat de grote meerderheid van de bevolking zich voor de dagelijkse gezondheidszorg dient te wenden tot paramedici in dispensaria en rurale gezondheidscentra. Deze bevinding benadrukt tevens dat de vorming van geneesheren in de toekomst niet al te zeer ten nadele van de vorming van paramedici zou mogen verlopen.

In verband met de aangewende middelen blijkt dat $52 \%$ ervan aan curatieve diensten wordt toegewezen, $18 \%$ aan voedingssupplementen, $10 \%$ aan de vorming van gezondheidswerkers, $9 \%$ aan preventieve diensten en $2 \%$ aan omgevingsfactoren die de gezondheid beïnvloeden. Zeer belanrijk is dat ongeveer $60 \%$ van de gezondheids- en ziekte-uitgaven door niet-Rwandese fondsen worden gedragen. Hienuit blijkt duidelijk de grote kwetsbaarheid van het land in de sector gezondheid en ziekte.

Het is bekend dat én van de redenen van het onbevredigende van de situatie gelegen is in het feit dat de vormingspatroon van de gezondheidswerkers een copie is van wat in Westerse landen gangbaar is. Deze werkwijze is vaak irrelevant in ontwikkelingslanden. Hetzelfde geldt voor de verzorgingsin- 
frastructuur, welke ingegeven werd door die in geindustrialiseerde landen en niet aangepast is aan de gezondheidsnoden van gemeenschappen in ontwikkelingslanden.

De verplichting zich in ontwikkelingslanden te richten tot populaties eerder dan tot individuen heeft verregaande sociale, politieke, estische en onderwijs-implicaties. Een effectief functioneren in deze context vereist een wel doordacht systeem, dat de schaarse middelen optimaal benut.

Anderzijds zal, hoe zorgvuldig dit systeem ook is uitgewerkt, het uiteindelijk rendement ervan grotendeels functie zijn van de vorming en werkwijze van de gezondheidswerkers. Een cruciaal punt in dit verband is het delegeren, door geneesheren, van verantwoordelijkheden aan niet-geneesheren. De breed verspreide schoorvoetendheid om dit te doen maakt wellicht én van de meest ernstige hinderpalen uit bij het verstrekken van de passende gezondheids- en ziektezorgen.

In ontwikkelingslanden werd gepoogd de onderwijsprogramma's van geïndustrialiseerde landen aan te passen aan de lokale noden van ontwikkelingslanden. Op universitair vlak beperkte dit zich evenwel tot het toevoegen van een dienst van preventieve geneeskunde in de schoot van de Faculteit. In deze situatie zal pas dan echt verandering komen wanneer de Faculteiten van Geneeskunde en de Universiteit volledig bewust zullen geworden zijn van het feit dat hun studenten en afgestudeerden op verschillende verantwoordelijkheidsniveaus dienen werkzaam te zijn, waarbij de gezondheidsproblemen van grote gemeenschappen even belangrijk, zoniet belangrijker zijn dan de op het individu afgestemde verzorging in een klinisch milieu. In dit verband vinden zowel het concept van het gezondheidsteam als dit van de geïntegreerde gezondheidszorg meer en meer ingang.

Last but not least wordt ook meer en meer gestreefd naar zelfhulp op maat van minder omvangrijke gemeenschappen.

Eén van de belangrijkste conclusies is wellicht dat de medische vorming in ontwikkelingslanden zoals Rwanda, aan de werkelijke gezondheidsnoden van de gemeenschap dient aangepast te worden wat, vanwege de medische Faculteiten, een emstige psychologische bewustwording en inspanning vergt. Een mogelijke benadering zou erin kunnen bestaan dat medische Faculteiten bij de opleiding een intenser gebruik maken van en bijdrage leveren tot de bestaande eerstlijnsinfrastructuur. Deze werkwijze zou het vereiste contact met de realiteit waarborgen en tevens een continue kwaliteitsverbetering van de gezondheidsvoorlichting en van de ziekenzorg toelaten. 
Uit wat voorafgaat is het duidelijk dat deze nieuwe werkwijze impliceert dat nieuwe benaderingen van curricula en van praktijkvoering worden ontworpen en dat zich, in zonderheid in academische middens, een mentaliteitsverandering voordoet.

Zijn echter niet het voortdurend in vraag stellen en het aanvaarden van nieuwe uitdagingen precies de opdrachten zowel van de Universiteit als van de medische samenwerking in ontwikkelingslanden ?

\section{Bibliographie}

De Schaepdryver, A. en Gatera, G. (1980): Projekt Gent-Butare 1966-1980. In "Liber Memorialis 1930-1980. Faculteit der Geneeskunde. Rijksuniversiteit Gent", 308-320. Alumni Fonds- Medische Faculteit Gent, Gent.

De Schaepdryver, A. (1983): Collaboration Nord-Sud dans le domaine de l'enseignement médical. In "Collaboration Médicale Axe Nord-Sud", 9-21. Fondation Heymans, Gand

De Schaepdryver, A.F. (1983): Education and Training: Discussion. In "Health in Developing Countries", 142-147. International Colloqium. Royal Academies of Medecine of Belgium, Brussels.

Janssens, P. (1962): Heeft de Belgische Tropische Geneeskunde nog toekomst? Verhandelingen Kon. VI. Acad. Gen. Belgie, 14, 16-80. 